\title{
A sustentabilidade como fator de competitividade nas micro e pequenas empresas: um projeto competitivo utilizando ferramentas sustentáveis
}

Recebido em 14.08.2015. Aprovado em 20.11.2016 Avaliado pelo sistema double blind review

\author{
Antonio Tavares Costa \\ ratcosta@gmail.com \\ Universidade Federal do Amapá - Macapá - AP \\ Elliarllen Patrick Alves \\ Faculdade Machado de Assis - Fama - Curitiba - PR \\ Claudia Borges Bastos \\ Faculdade Machado de Assis - Fama - Curitiba - PR \\ Ivanildo da Silva Feitosa \\ Faculdade Machado de Assis - Fama - Curitiba - PR
}

\section{Resumo}

A competitividade entre as organizações empresariais esta a cada dia mais acirrada, obter uma vantagem com relação às outras é o que muitas buscam, porem sem um planejamento estratégico elaborado de forma que venha a gerar lucro e agregar valor a marca, não se pode obter tal vantagem. Superar a concorrência utilizando metodologias e recursos que hoje estão disponíveis e acessíveis para toda e qualquer empresa, é um desafio que muitas dessas ainda não conhecem e acabam por fazer parte de uma estatística onde muitas empresas fecham suas portas em menos de dois anos. Hoje a preocupação com o planeta e a sustentabilidade esta em foco, e as empresas sabendo utilizar dessa metodologia, podem começar a se tornar mais competitivas utilizando metodologias sustentáveis, sabendo utilizar os recursos e matérias primas de uma melhor forma onde essa empresa poderá obter um lucro e assim superar a concorrência. Utilizar metodologias sustentáveis é um elemento que faz com que toda empresa seja superior a soma das unidades dos negócios concorrentes, pois assim poderá a mesma ganhar mercado e ao mesmo tempo fidelizar e encantar clientes.

Palavras-chaves: Competitividade. Sustentabilidade. Metodologias Sustentáveis. Organizações.

\begin{abstract}
The competitiveness of business organizations is the increasing life erce, get an advantage over other sis what many seek, but without a strategic plan designed in a way that will generate ein come and add value to brand, you can not obtain such advantage. Outperform the competition by using methodologies and resources that are now available and affordable for any company, is a challenge that many of these still do not know and end up being part of a statistic here many companies close their door sin less than two years. Today the concern for the planet and sustainability is in focus, and companies know using this methodology, can begin to become more competitive using sustainable methods, knowing use of the resources and raw materials in a better way here this company can make a profit and well out pacing the competition. Using sustainable methodologies is one element that makes the entire company exceeds the sum of the business sun it's competing for the same so you can gain market share while retaining and delighting customers.
\end{abstract}

Keywords: Competitiveness. Sustainability. Sustainable Methods. Organizations. 


\section{Introdução}

Segundo os maiores estudiosos dos temas que envolvem gerenciamento, estratégias competitivas e sustentabilidade, a competitividade entre as empresas esta muito além da simples satisfação do cliente, para obter êxito no cumprimento da sua missão no mercado as empresas começam a adotar praticas sustentáveis obedecendo leis, normas, procedimentos e aplicação de metodologias agregadas a ferramentas gerenciais, fazendo com que o impacto ambiental seja menos poluente. Para as organizações a aplicabilidade dessas metodologias aumenta a lucratividade e melhora sua produtividade reduzindo desperdícios e maximizando 0 lucro, gerando um diferencial competitivo.

A sustentabilidade é a capacidade de não comprometer os recursos naturais e econômicos hoje existentes para gerações futuras utilizando da melhor forma possível esses recursos, que é a forma encontrada pelas empresas a adotarem metodologias sustentáveis para agregar valor a imagem fazendo com que seu publico alvo mantenha uma maior relação cliente-empresa, tornando-se alvo das mesmas com foco na fidelização dos clientes, atendendo a padrões ambientais, econômicos e sociais.

Saber utilizar os recursos tanto econômicos quanto naturais é um desafio para muitas empresas, encontrar métodos que tragam benefícios para a empresa e consequentemente para seu entorno, são iniciativas ainda tímidas no cenário empresarial, porem a partir da década de oitenta a sustentabilidade ficou ainda mais em evidencia, muitos empresários buscam aplicar essas ações na sua forma de trabalho, negócios sustentáveis cada vez mais estão tomando conta do mercado, utilizando de forma consciente os recursos disponíveis para a produção de bens de consumo, o acesso a informação e o maior grau de instrução do cliente de hoje aumenta a responsabilidade das empresas em encontrar uma metodologia atual e responsável, não esquecendo do seu alvo principal, o lucro. Tornar as empresas mais competitivas utilizando metodologias cada vez mais sustentáveis é um passo que deve ser dado gradualmente para que a sociedade não sinta um impacto tão fervoroso e o tenha como negativo, de forma essas empresas podem beneficiar-se com isso a médio prazo sentindo realmente o ganho de mercado com o uso de tais metodologias. Criando propostas que se façam melhorias socioambientais como uma forma de enriquecer a sociedade tornando o produto mais atrativo, enquanto o mercado econômico cresce de forma desenfreada, gerando impactos negativos para 0 meio ambiente e para a sociedade como um todo, sendo necessário reconsiderar a utilização desses recursos naturais para produção de produtos em que a própria sociedade impõe seu consumo, reduzir o consumo depende de mudanças de hábitos da sociedade em geral, a empresa dentro desse contexto trabalha paralelamente a essa temática porem preocupada também com a sustentabilidade econômica do seu negocio no mercado. Extrair vantagens competitivas dessa situação utilizando métodos e tecnologias em prol da sustentabilidade obtendo resultados significativos no aspecto econômico e financeiro de suas produções.

Numa sociedade cada vez mais evoluída com acesso a informação a melhoria das condições sociais e ambientais favorece a competição entre as empresas, deixando de lado o tradicional pensamento de custos adicionais, agregando valor a organização, essas preocupações com as dimensões sociais e ambientais oferece subsídio para a competitividade e com isso a empresa passa a obter resultados mais vantajosos compondo a vantagem sustentável, no decorrer do trabalho veremos as diversas formas de negócios sustentáveis, como se aliar a esta ferramenta hoje tão evidenciada e como gerar benefícios para a empresa de forma que isso se transforme em maximização de lucro. Este artigo propõe discutir as conotações das propostas de práticas sustentáveis com base em um eixo que possibilita que ela seja incorporada a empresa, com 0 objetivo de melhorar a produção e a diminuição de custos operacionais, segmentos estes que apontam as convergências alem de indicar a evolução nos resultados das estratégias sustentáveis do gerenciamento empresarial.

\section{Competitividade e Sustentabilidade}

O conceito de competitividade discutido atualmente segue, em sua maioria, a definição proposta por Michael Porter, importante ícone dos princípios fundamentais da competitividade. Segundo Porter (1993), a competitividade é a habilidade ou talento resultantes de conhecimentos adquiridos capazes de criar e sustentar um desempenho superior ao desenvolvido pela concorrência. Para Porter (1993), o conceito mais adequado para competitividade é a produtividade. A elevação na participação de mercado depende da capacidade das 
empresas em atingir altos níveis de produtividade e aumentá-la com o tempo. Reflexões feitas por Harris e Ogbonna (2001), apontam que o desempenho pode ser derivado da geração ou inovações valiosas do mercado, construindo barreiras à imitação ou aprendendo e mudando mais rapidamente que a concorrência, não apenas como resultado do poder de mercado, mas é derivado da mistura dos recursos da empresa. $A$ competitividade, de acordo com a interpretação de Porter (1993), é vista e compreendida sob diversas óticas, impulsionado por variáveis como taxas de câmbio e de juros, déficits e políticas governamentais, recursos naturais, e, acima de tudo, diferenças de práticas administrativas.

A sustentabilidade foi introduzida no início da década de 1980 por Lester Brown, fundador do Wordwatch Institute, que definiu comunidade sustentável como a que é capaz de satisfazer às próprias necessidades sem reduzir as oportunidades das gerações futuras. Diniz da Silva (2009) explica que o interesse por sustentabilidade se originou durante a década de 1980, a partir da conscientização dos países em descobrir formas de promover 0 crescimento sem destruir o meio ambiente, nem sacrificar o bem-estar das futuras gerações. Desde então, o termo se transformou em cenário para causas sociais e ambientais, principalmente no nos negócios, onde prevalece a idéia de que de geração de lucro para os acionistas, ao mesmo tempo em que protege o meio ambiente e melhora a qualidade de vida das pessoas com que mantém interações.

Diniz da Silva, (2010) considera que em termos econômicos, a sustentabilidade prevê que as organizações têm que ser economicamente viáveis, face ao seu papel na sociedade e que deve ser cumprido levando em consideração o aspecto da rentabilidade, dando retorno ao investimento realizado pelo capital privado. Do ponto de vista social, a organização deveria proporcionar boas condições de trabalho e em termos ambientais, a empresa deveria pautar-se pela ecoeficiência dos seus processos produtivos, oferecendo condições para 0 desenvolvimento de uma cultura ambiental organizacional, adotando uma postura de responsabilidade ambiental e buscando a não contaminação de qualquer tipo do ambiente natural. Também seria importante procurar participar de todas as atividades propostas pelas autoridades governamentais locais e regionais no que diz respeito ao meio ambiente. 0 crescente interesse pela sustentabilidade tem apresentado impactos nas estratégias das empresas. São cada vez mais cobradas demonstrações de que a empresa tem um foco sustentável. Esta cobrança é feita tanto pela sociedade como pelos seus clientes corporativos, governos, dentre outros (SGASRBI, 2008).

A relação existente entre sustentabilidade e competitividade empresarial, pode ser observada a partir do momento em que se depara com as vantagens competitivas individuais das empresas, quando as mesmas exercem atividades empresariais do mesmo ramo, mas adotam estratégias e comportamentos diferentes. Quer dizer que, de algum modo, essas organizações sofreram algum impacto seja de dentro para fora como de fora para dentro.

O atual cenário do mercado expõe diversas técnicas que podem ser utilizadas por essas empresas, fazendo com que aquele material usado na produção, antes utilizado de maneira errônea, possa passar a ser utilizado com metodologias sustentáveis fazendo com que a empresa possa ser mais competitiva a partir do momento em que esse novo método traga resultado econômico satisfatório podendo esta empresa ser mais vantajosa em sua oferta ao mercado.

Atualmente muitos estudiosos procuram um forma das empresas se auto sustentarem, trazendo benefícios a elas mesmas e ao seu entorno, a sustentabilidade é muito discutida hoje em dia, se realmente é possível colocála em pratica sendo que ainda há muitas organizações que não se importam com essas causas, porem devemos observar que quando não se trata de sustentabilidade dificilmente toda e qualquer empresa poderá se manter no mercado, propor novas soluções de negócios sustentáveis, elaborar um método de trabalho mais eficiente e menos dispendioso ao ambiente como um todo, utilizar da melhor maneira possivel todos os recursos propostos gerando um maior retorno a empresa e a sociedade.

É evidente, contudo, que a sustentabilidade perfeita não pode ser efetivada, tendo em vista que os estragos feitos ao meio ambiente, bem como a perda de capital natural, são já consideráveis. Mas o conceito de 
sustentabilidade pode servir para frear uma destruição mais acelerada dos recursos naturais (BINSWANGER, 2002).

A sociedade esta cada vez mais exigente, desta forma as empresas vêem-se obrigadas a alterar ou modificar sua forma de trabalho perante o publico externo, isso significa dizer que adotar metodologias sustentáveis pode acarretar resultados favoráveis a esta, uma vez que as praticas sustentáveis tem imagem positiva perante a sociedade cada vez mais preocupada com manejo consciente dos recursos naturais.

\section{Metodologias Sustentáveis como vantagem competitiva}

Saber fazer com que a sustentabilidade seja algo constante na organização é um desafio porem muitas utilizam ferramentas hoje explicitas para serem aplicadas e desenvolvidas para a maioria das empresas obtendo assim um resultado satisfatório para seu negócio. A implantação de um programa sustentável dentro de uma organização traz benefícios não somente a ela mais a toda sociedade em torno, para as empresas a capacidade de competir no mercado utilizando estratégias sustentáveis que gere lucro é uma forma consciente de suprir custos adicionais, tornando-os como investimentos retornáveis, nesse sentido considerado pelo publico externo como uma empresa preocupada com o planeta, o que é favorável a vida útil dessas empresas, não esquecendo que o principal objetivo de uma organização privada é o lucro e que sem esse retorno torna-se inviável a implementação das metodologias sustentáveis. Atender as necessidades da geração presente sem comprometer a possibilidade das gerações futuras atenderem as suas próprias necessidades, é uma questão que deve ser trabalhada desde sempre, já que não se pode esquecer de que os recursos utilizados de maneira errônea podem prejudicar a todos.

O Brasil já vem experimentando um ciclo de sustentabilidade. 0 ciclo virtuoso começa com o consumidor exigindo do varejo produtos ambientalmente sustentáveis, que por sua vez exigem dos fabricantes produtos sem impacto ambiental, e a indústria exige dos seus fornecedores matérias-primas limpas. (Revista Brasileira de Administração, Ano 2008, $n^{\circ}$ 67)

A proposta da utilização de metodologias sustentáveis deve acontecer de forma geral e permanente, a construção deste cenário significa não só uma nova forma de trabalho, mas também uma nova forma de construção de todos os processos que contribuem para a evolução do homem, uma vez que estes métodos darão suporte como acima mencionado, as próximas gerações. Metodologias estas como:

- $\quad$ Produção mais Limpa $(\mathrm{P}+\mathrm{L})$; consiste na qualidade e eficiência no processo de produção diminuindo 0 desperdício.

- $\quad$ Cinco Menos que são Mais (5 - que são +); é a diminuição do consumo de energia, água e matéria prima, diminuindo a poluição e lixo, aumentando conseqüentemente a produtividade, competitividade, lucro, qualidade e satisfação do cliente.

- Diagnóstico Rápido Participativo (DRP); trata do estudo do empenho da empresa para um resultado de proposta de melhoria com a participação de todos da empresa.

- $\quad$ EcoEficiência (2 E); é o aprimoramento de seu sistema, trabalhando paralelamente com o sistema de gestão ambiental, gerando benefícios para o todo, através da produção ecológica.

Algumas análises procuram mostrar como o uso consciente dos recursos pode surpreender muito no final do processo de produção, conseguindo então, ser mais competitivo de forma que aquele resíduo no processo de produção seria perdido gerando prejuízo as empresas, torna-se uma vantagem perante aos concorrentes que ainda não utilizam dessa ferramenta de gestão, sendo que a falta dessa preocupação com seu próprio processo dentro de uma organização ainda é uma barreira a ser ultrapassada pelo próprio responsável em gerar ganhos a esta e a futuras gerações, o ser humano.

Assim, as demandas de apoio às MPE's com relação à gestão ambiental dizem respeito a:

- $\quad$ Suporte técnico para as empresas no que se refere a consultoria para avaliações ambientais prévias, visando a uma caracterização da situação ambiental da organização; 
- Apoio para elaboração e implementação de sistema de gestão ambiental, mediante orientação e busca de outras fontes de recursos;

- Indicação de instituições e profissionais especializados em gestão ambiental;

- Apoio às empresas para certificação de sistemas integrados de qualidade, de meio ambiente, saúde e segurança;

- $\quad$ Disseminação de procedimentos para melhoria da qualidade de vida e da saúde;

- $\quad$ Orientação para disseminação de tecnologias menos poluentes;

- $\quad$ conscientização dos empresários em face dos efeitos que suas atividades podem causar ao meio ambiente;

- conhecimento dos requisitos legais de meio ambiente, de saúde e segurança ocupacional e de responsabilidade social;

- $\quad$ identificação de ameaças e oportunidades de negócios para as empresas;

- $\quad$ disponibilização de informações atualizadas acerca de gestão ambiental;

- $\quad$ disseminação da variável ambiental em todo o Sistema Sebrae;

- $\quad$ sensibilização do segmento empresarial para a necessidade de melhorar seu desempenho ambiental;

- $\quad$ estabelecimento de cooperação com instituições interessadas em apoiar a melhoria do desempenho ambiental das MPE's;

- difusão de conceitos de conservação e preservação ambiental;

- formação de recursos humanos em gestão ambiental voltada tanto para técnicos do Sistema Sebrae como para instituições parceiras e MPE's.

\section{A Implantação de um Sistema de Gestão Ambiental (SGA) nas Organizações}

A adoção de práticas e procedimentos que garantem a melhoria continua do desempenho ambiental é de fundamental importância, pois assim alem de se tornar mais produtiva, a empresa também passa a ser mais competitiva no sentido de se gerar um maior lucro e aumentando sua vantagem com relação a concorrência.

A política de meio ambiente, é um principio de ação que orienta todo o processo de implementação do Sistema de Gestão Ambiental na empresa, a mesma deve desenvolver uma política de meio ambiente que seja adequada suficientemente para lhe trazer vantagens competitivas e ao mesmo tempo para que possa ser cumprida. A implementação de um Sistema de Gestão Ambiental pelas empresas é opcional, porem uma vez que trabalhada e certificada pelas organizações internacionais, a mesma passa a seguir fielmente esse sistema. Como tornar-se ambientalmente responsável ao menor custo e manter se competitivo? Esse é um desafio que desde pequenas, medias ou grandes empresas têm que enfrentar na atualidade, o SGA é a ferramenta para que qualquer empresa possa programar um processo de melhoria continua de seu desempenho ambiental, essa implementação acontece em cinco estágios, cada um destes é definido com um principio da Norma ISO 14004, a norma usada como referencia, no conjunto os cinco estágios cobrem as atividades em toda gestão do processo produtivo.

- $\quad$ Comprometimento e definição da política de meio ambiente;

- Planejamento do SGA

- Implementação do SGA

- Medições e Avaliações

- $\quad$ Revisão e Melhoria 
O SGA é mais que uma estratégia de prevenção, representa uma vantagem competitiva e um diferencial de mercado, as melhorias que introduz no processo reduz os custos de forma racional, otimizando o trabalho e evitando todo tipo de desperdício podendo gerar ainda novos negócios, o sucesso do SGA depende do comprometimento em vencer o desafio e melhorar continuamente os processos de produção de uma empresa. Não podendo a alta diretoria deixar minimizar essa pratica na empresa, pois todo seu quadro de pessoal ira refletir na produção da mesma, podendo ate gerar conflitos onde o principio da iniciativa desse sistema começa na alta direção. Utilizar estratégias sustentáveis que gerem lucro é uma forma agradável de suprir custos adicionais, tornando-os investimentos retornáveis.

\section{Certificação ambiental e sua importância.}

A certificação do Sistema de Gestão Ambiental é o instrumento que a empresa utiliza para demonstrar às partes interessadas sua relação positiva com o meio ambiente. Por isso, é indispensável que os instrumentos normativos orientadores da estruturação dos SGA's e o credenciamento dos organismos certificadores tenham aceitação e credibilidade internacionais. $O$ credenciamento também chamado de "acreditação" dos organismos certificadores são feitos segundo critérios rígidos e bem fundamentados, tendo, como principais requisitos, estrutura organizacional, metodologia de trabalho e qualificação do corpo técnico adequados aos objetivos e responsabilidades inerentes à atividade de certificação. A comprovação dos requisitos da ISO 14001 é feita por entidade independente.

\section{Diminuindo os Custos para Aumentar o Lucro através da Sustentabilidade}

Segundo uma das leis da física, a Lei da Termodinâmica em que diz que em uma transformação nunca podemos aproveitar tudo o que havia no estado inicial, sempre perdemos uma parte, portanto além do produto que queremos obter sempre teremos também resíduos indesejáveis. Além disso, a maior parte das coisas que produzimos tem uma curta vida útil sendo depois dispensadas e geralmente devolvidas ao ambiente, mas como são produtos artificiais, a natureza não sabe bem como aproveitá-las ou mesmo não se aproveitam.

Diminuir o consumo de materiais como água, energia, e matéria-prima, diminuindo consequentemente a quantidade de lixo e poluição, e ao mesmo tempo aumentando a produtividade, competitividade e o lucro como também maior satisfação do consumidor e maior qualidade ambiental. Otimizar o sistema de produção fazendo com que aumente 0 aproveitamento, podendo diminuir o consumo de recursos diminuindo consequentemente o desperdício permitindo um valor final de produto mais competitivo e mais lucrativo, o cliente se satisfaz pelo menor preço e porque a cada dia a consciência ecológica cresce e posturas voltadas a qualidade ambiental se popularizam. Antes o empresário utilizava a formula de preço de custo mais lucro, sendo igual ao preço de venda, hoje em dia esse valor é definido pela alta concorrência no mercado obrigando os empresários a adequarem seu preço de custo a fim de manter seu lucro, sendo assim a produção deve ser; Economicamente viável, Ecologicamente sustentável e Socialmente justo.

\section{0 planejamento sustentável voltado a competição}

As empresas hoje buscam uma forma de cativar o cliente e ao mesmo tempo agregar na mesma uma referência para que seu cliente tenha a sensação de estar fazendo o correto, muitas empresas utilizam ate o sistema de sustentabilidade como marketing o que acontece muito, porem os órgãos de fiscalização estão atentos para esta crescente situação, mesmo assim muitas empresas preocupadas realmente, conseguem ser sustentáveis e mais competitivas no sentido de melhorar sua produção e diminuir seu custo sendo mais competitiva.

Quanto maior a produção de resíduos maior o desperdício de matérias-primas, maior o potencial de poluição e provavelmente menos poder de competição, no caso do setor produtivo. As sobras produzidas por uma empresa, podem ser a matéria-prima de um outro processo industrial. Pode-se desenvolver um setor específico na própria unidade geradora, ou vender a terceiros. A necessidade de uma regulamentação dentro da empresa que permita o manuseio de matérias na natureza, de uma forma que venha a proteger o ambiente tem sido objeto de pautas em muitas empresas, a aceitação por esse novo modelo de competição e sistema de produção para alguns vem a gerar custos, porem pode ser considerado para muitos como um investimento que retornara o lucro em médio prazo. A visão predominante por certos empresários é na forma de como fazer a existência da ecologia versus economia, de um lado veem-se os benefícios sociais e ao meio ambiente de correntes desse 
novo modelo, porem do outro lado veem-se os custos para esse investimento, custos que podem gerar aumento de preço e redução da competição, com essa questão, o progresso para a qualidade ambiental, acaba por se tornar uma espécie de luta pela direção, que seria como se um lado se empenhasse por normas severas e outro pelo equilíbrio ecológico.

As normas ambientais elaboradas de forma adequada são capazes de desencadear inovações que reduzem os custos totais de um produto ou aumentam seu valor. Essas inovações permitem que as empresas utilizem uma gama de insumos de maneira mais produtiva - abrangendo matéria prima, energia e mão de obra compensando assim, os custos da melhoria do impacto ambiental e resolvendo o impasse. Em ultima instância, 0 aumento da produtividade dos recursos favorece, em vez de comprometer, a competitividade das empresas. (PORTER, 1999, p. 372)

Elaborar um planejamento que seja sustentável e que traga resultados em forma de lucro é muito além que apenas a decisão de implantar um sistema dentro da empresa, se deve a questão dos impactos ao ambientes externo ou interno, esse planejamento colocado a pratica deve estar em constante atualização e moldado conforme o segmento de cada empresa, não esquecendo do compromisso uma vez assumido por parte de uma empresa para a minimização dos impactos trazendo a ela uma vantagem em relação as concorrentes.

Para Fleury e Fleury (2003) essa abordagem prioriza análise de mercados, da competição, do entendimento da posição relativa de cada empresa em sua indústria ou segmento produtivo como elementos primordiais no processo de formulação da estratégia. Os principais focos de analises são produtos, consumidores e competidores, e a estratégia da empresa deve ser resultante da identificação de tendências e de oportunidades. De acordo com a linha de pensamento de Barney (2001) os recursos e as potencialidades podem ser mais evidentes através da competição e das diferenças entre as empresas, o que pode ajudar a explicar porque a autoperformace de determinados empreendimentos é mais consistente do que outros. Assim a utilização de indicadores de que forneçam a informação necessária para projetar estratégias de competição para a articulação com a preservação do meio ambiente e a melhoria do ambiente externo dando suporte e estrutura para a promoção da sustentabilidade como sendo uma estratégia para alavancar a imagem da marca. A busca pela sustentabilidade empresarial para o sucesso na luta da competitividade reflete quando o consumidor sente que aquela empresa busca melhorias adequadas a realidade hoje vivida, sendo que o sucesso para tal vai muito alem de apenas usar do marketing para promover a marca.

\section{EMPRESAS FOCADAS NO CLIENTE CONSCIENTE.}

As empresas com foco no cliente não podem apenas buscar uma forma de encantá-los apenas pela cordialidade, bom atendimento, menor preço, promoções e etc., o cliente de hoje esta mais exigente e mais preocupado com o planeta.

Então como conquistar o cliente através de outras metodologias? Fazer o cliente sentir que faz sua parte na preservação do meio ambiente também é uma forma de conquistá-lo, investir na competição através da sustentabilidade é a maneira encontrada por muitas empresas para encantar seus clientes, muitas hoje, ou quase todas, tem algum tipo de sistema voltado a questão da sustentabilidade empresarial, a fim de se tornar mais competitivas no preço dando ao cliente ao mesmo tempo a satisfação da estar contribuindo para as causas ambientas. Hoje as promoções da empresas, ate mesmo seu marketing e propaganda é voltado para essa questão, o assunto sustentabilidade está em evidência e as empresas devem acompanhar o ritmo em que o consumidor esta envolvido, nos veículos de comunicação a degradação ambiental e a atual situação do planeta estão sendo freqüentemente expostas, tais informações propagadas vem a nos incentivar a adotar certas atitudes sustentáveis, ate mesmo em beneficio próprio, dentro das sociedades cada um deve atentar-se para suas responsabilidades e as empresas começam também a adotar esse comportamento. Ser uma empresa sustentável não corresponde apenas a si, funciona como uma via de mãos dupla, para essas empresas de tal importância, sendo que ao mesmo tempo em que a empresa contribui com a sociedade e com 0 ambiente, também retorna a mesma os benefícios dessa marca. Um gestor que adere ao sistema sustentável dentro de sua organização estará baseando-se em três fatores importantes: 0 ambiental, o social e o econômico. 
Ambiental: toda empresa utiliza de maneira direta ou indireta os recursos naturais. A partir do momento que uma organização adota uma postura sustentável, ela passa a utilizar estes recursos de maneira mais racional. Algumas atitudes, por mais que pareçam pequenas, podem ajudar a diminuir diversos impactos ambientais.

Social: uma empresa exerce grande influência social e a partir do momento que se compromete a oferecer produtos, prestar serviços e adotar atitudes diferenciadas, deixa claro qual é a sua postura dentro da sociedade. Nessa mesma linha, a gestão empresarial sustentável tem um papel muito importante. A empresa serve de exemplo aos seus funcionários e aos seus stockholders de forma geral, que são motivados a mudar os seus atos e serem mais conscientes quanto ao meio ambiente.

Econômico: do ponto de vista econômico, ser uma empresa sustentável pode ser também bastante lucrativo. A começar pelos recursos naturais, se você utilizá-los da melhor maneira, pode ter menos gastos, ou se passa a reaproveitar alguns materiais, também pode evitar desperdícios. Sem contar que hoje o governo já oferece para as empresas sustentáveis diversos incentivos fiscais como a facilidade de créditos e a isenção de determinados impostos.

As empresas focadas na satisfação do cliente cada vez mais preocupado com o que é sustentável utilizam muitas vezes dessa ferramenta para propagar sua marca com isso hoje na mídia é freqüente ver algum tipo de programa sustentável ligado aquela empresa, seja na utilização consciente dos recursos naturais, ou reciclagem de embalagens, do reuso de artigos antes descartáveis, ou mesmo o consumo consciente de energia e água, refletindo para as organizações em forma de lucro, uma vez que essa conscientização diminuirá os custos de produção e aumentara sua competição no mercado.

As empresas envolvidas no ramo da competitividade empresarial, como forma de superar a concorrência, apostam na qualidade do atendimento. Possuem uma preocupação constante sobre o modo como a empresa é vista pelo publico externo. (BEKIN, 2005, p. 63)

Na maioria das vezes os olhares do empresariado ficam voltados exclusivamente para o atendimento externo sendo que no atual momento em questão essa pratica passa a se tornar retrograda e isso faz com que os investidores permaneçam com a visão ofuscada, focando apenas no atendimento e isso acaba por impedi-los de enxergar uma das causas de fator determinante, o cenário atual.

\section{A política de governo para a sustentabilidade}

O Estado no processo de desenvolvimento sustentável se faz extremamente importante, pois ele constitui um conjunto de fatores para que empresas e organizações localizadas naquela área se façam seguir de acordo com as normas que o mesmo institui.

Garantir a qualidade do meio ambiente e a qualidade de vida de acesso aos recursos naturais são objetivos fixados para que se sinta o efeito da sustentabilidade na política de governo, o comprometimento com a sustentabilidade tem que desencorajar aquilo que cause ameaças a saúde, a poluição e o desperdício de matérias como a água e energia é o que o estado deve priorizar para que seja intitulado estado sustentável. As políticas de governo voltadas a qualidade de vida e hábitos de consumo que objetivam o manejo consciente, são trabalhadas de forma em que todo o meio esteja envolvido desde as empresas privadas o próprio estado e a sociedade em geral.

A política de governo para a sustentabilidade deve conter medidas para estimular aqueles setores que efetivamente adicionem valor, contribuindo menos para a depleção e degradação. (CAVALCANTI, 2002, p. 35)

Tais políticas têm de ser capazes de redirecionar o curso dos eventos econômicos, pois o capital natural e 0 econômico devem estar alinhados para que um seja sustentador do outro. Os objetivos de uma sociedade consciente com o manejo do meio ambiente e seus recursos deve permanecer na linha de pensamento em que as gerações futuras possam satisfazer suas necessidades de forma durável e ecologicamente responsável, pra que o capital humano não se deteriore. 


\section{0 empreendedorismo focado na sustentabilidade}

Empreendedorismo nada mais é que o envolvimento de uma ou mais pessoas em processos onde levam a transformação de uma ideia em oportunidade. A implementação dessas ideias oportunas leva a criação de um negócio, este que pode vir a ser um modelo de sucesso, dependendo claro, do foco desse empreendedor na sua empresa. Empreendedor é aquele indivíduo que não se enquadra em um ambiente monótono e repetitivo, e sim aquele que busca informações para explorar as oportunidades, este mesmo indivíduo melhora seu conhecimento e inova naquilo que já existe ou até mesmo cria novas oportunidades de negócios.

O empreendedor é aquele que destrói a ordem econômica existente pela introdução de novos produtos e serviços, pela criação de novas formas de organização ou pela exploração de novos recursos e materiais. (SCHUMPETER, 1949)

Para outros autores o empreendedor é definido de varias formas, um, como sendo responsável por mudanças e inovações dentro de um negocio já existente, outro como sendo um perfeito identificador de oportunidades sendo um individuo curioso e atento as informações do mercado, o empreendedor também cria novos negócios e os faz de maneira em que não se vê com frequência, tanto que estes são considerados pelo mercado como aquele que cria um equilíbrio e se posiciona de forma clara e positiva em um ambiente não favorável, ou seja, turbulento e caótico. Essa definição seja por qual for, encontra-se sempre aspectos indiscutíveis das características do empreendedor, como, a iniciativa em criar, a perseverança e paixão pelo que faz, utilizar a melhor maneira possível dos recursos disponíveis, transforma o ambiente social e econômico e não se perde a vontade e animo nas possiveis falhas ou fracassos, assumindo riscos calculados e não deixando de ser bem sucedido por isso.

O processo empreendedor envolve todas as funções, atividades e ações associadas com a criação de novas empresas. Em primeiro lugar, 0 empreendedorismo envolve o processo de criação de algo novo, de valor. Em segundo, requer a devoção, o comprometimento de tempo e o esforço necessário para fazer a empresa crescer. E em terceiro, que riscos calculados sejam assumidos e decisões críticas tomadas, é preciso ousadia e ânimo apesar de falhas e erros. (DORNELAS, 2008, p. 23)

No empreendedorismo, a colocação de uma idéia sendo ou não nova no mercado, não se remete ao sucesso do mesmo, pois o que realmente a faz acontecer é o comprometimento do indivíduo com o negócio e desenvolvimento de uma ideia diferencial no mercado, sendo competitivo e obtendo vantagens com relação aos seus concorrentes. Existia o mito de que o empreendedor era nato, não sendo possível a "criação" de uma figura empreendedora, porem esse paradigma foi quebrado, sendo mostrado que o empreendedor pode sim ser treinado ou até mesmo surge por necessidade de empreender para arrecadar valor, sendo este chamado de empreendedor por necessidade.

A tendência do mercado no do final do século vinte aos dias atuais vem sendo mostrado pela mídia como a preocupação com o planeta, ou seja, empreendedores estão buscando soluções e estratégias voltados a sustentabilidade, ganhando espaço no mercado utilizando dessa metodologia, pois a sociedade se faz presente com a questão e acabam por ter essa preocupação até para que seu negócio também seja sustentável economicamente, fazendo com que muitas ideias de negócios sustentáveis e empreender com sustentabilidade seja 0 alvo de muitos casos de sucesso.

Desenvolver um negócio com sustentabilidade socioeconômico-ambiental são diretrizes hoje difundidas como ações para o desenvolvimento das micro e pequenas empresas principalmente na região da Amazônia onde os recursos estão mais próximos dos empreendedores e onde a sociedade ver de perto a real condição da empresa tida como sustentável e ecologicamente correta. 
No estado do Amapá, estado sendo o mais preservado do país, muitos casos de sucesso voltados ao empreendedorismo sustentável estão sendo motivados por meios de parcerias a acrescentarem no mercado esses produtos

A partir de 1999, um grupo de mulheres, buscando reforçar o orçamento familiar, viu em um projeto da deputada Janete Capiberibe, uma oportunidade de negócio. Foram atrás de parcerias e contaram com o apoio do Governo do Estado e Sebrae, pautadas em u projeto sustentável, essas mulheres receberam capacitação e orientação técnico-empresarial. Dentro desse contexto, a produção de artefatos de madeira surgiu no estado do Amapá como uma alternativa para o desenvolvimento local. (SEBRAE-AP, Histórias de Sucesso, 2003)

A ideia de empreender com sustentabilidade pode ser fator de competitividade para as empresas, pois gera uma imagem positiva e até fideliza clientes. Portanto aderir a essa metodologia não pode ser considerado apenas para o marketing, se deve assumir esse compromisso e colocá-lo na pratica para o bem-estar social e 0 sustento do planeta.

As empresas fora dos padrões estabelecidos pelo cliente hoje mais exigente, consciente e esclarecido, serão alvo de veto de compras por parte de uma maciça de consumidores, essas empresas predadoras que causam a degradação dos recursos naturais terão que, em primeiro, tomar medidas que possam se enquadrar nas metodologias e padrões sustentáveis para se alinhar no mercado ou, em segundo, perderam com a alta competitividade que outras empresas terão pelo uso consciente desses métodos, a ação de compra por parte do consumidor tornou-se fortemente influenciada por esse respeito ao meio ambiente.

Novas ideias só surgem quando a mente da pessoa está aberta para que isso ocorra, ou seja, quando está preparada para experiências novas. Assim, qualquer fonte de informação pode ser um ponto de partida para novas ideias e identificação de oportunidades de mercado. Informação é a base de novas ideias, estar bem informado é o dever de qualquer empreendedor. (DORNELAS, 2008, p. 41)

As novas ideias, colocadas na estruturação da empresa são a prova de que hoje as empresas sentiram essa necessidade de incorporar no seu meio empresarial a preocupação e respeito ao meio ambiente, hoje essas empresas figuram em suas agendas de trabalhos ações exclusivas e voltadas e essa questão, a maior parte dos empreendedores incorporam a modernização e estratégias competitivas os negócios, essa busca pela competitividade através da sustentabilidade assimila um discurso de liderança sendo que os empreendedores de sucesso hoje possuem alicerces para tal propagação. A sustentabilidade tomou um conceito de força para as empresas para sua posição no mercado, já que a mídia faz com que o consumidor se torne mais consciente, o que antes, para as pessoas menos familiarizadas com o assunto parecia no mínimo estranha, como uma empresa pode ser sustentável se a mesma retira os recursos do meio ambiente? Porem não se pode haver negócios que se sustentem sem a preservação do meio ambiente, por isso as empresas começaram a utilizar das metodologias em que a produção seja mais eficiente e menos degradante aos recursos, trazendo benefícios a essas empresas que farão com que elas estejam a um passo a frente no mercado hoje tão concorrido.

Com Porter (1980), o foco da analise da competitividade desloca-se das organizações para seu ambiente, sobretudo os chamados anéis de competitividade, a saber: estratégia, estrutura e rivalidade das empresas; condições de demanda; condições de fatores; indústrias correlatas e de apoio. Para Barney (1991), as concepções de competitividade partem da idéia de homogeneidade dos recursos detidos, em longo prazo, pelas firmas. Os diferenciais competitivos alcançados seriam diluídos entre outras organizações, em longo prazo, por meio de diferentes processos como aprendizagem concorrencial, transferência de corpos técnico-gerenciais, sistematização e difusão de saberes na mídia e por meio do contato intergerencial. Encontrar o equilíbrio entre a sustentabilidade e a competitividade é um fator determinante para o sucesso da empresa, que aloca essa metodologia para si, assim, fazendo com que seus clientes e potencias se fidelizem a tal marca pelo seu comprometimento com a questão hoje tão discutida e trabalhada para que gerações futuras também possam utilizar dos recursos disponíveis a atender suas necessidades. 
O verdadeiro empreendedor é aquele que busca a tendência para fazer dela uma vantagem competitiva, empreender com responsabilidade e agregando valor a empresa é quase que uma tarefa de vital importância para que esses empreendimentos permaneçam no mercado, porem não apenas utilizar para fins de marketing e sim assumir o compromisso com a chamada "onda verde".

\section{Conclusão}

A busca constante pela melhoria nas estratégias competitivas é algo em que as empresas investem para terem uma vantagem no mercado.

A influência da sustentabilidade na melhoria da competitividade de um empreendimento instalado reforça 0 quão necessário se faz a utilização desse método de trabalho e estratégia nesses empreendimentos, os avanços do mercado na produção e retirada de matéria prima do meio ambiente são importantes no sentido de contribuir para a humanidade, porem, para algumas empresas existe o paradigma da sustentabilidade 0 que ainda precisa ser estudado por esses empreendimentos que tem essa metodologia de não contribuir para 0 meio social e econômico, ainda esquecem que os benefícios serão ainda maiores para a própria empresa, evidências demonstram que as empresas tornam-se mais competitivas a partir da implementação desse sistema, ainda que num primeiro momento venham a representar custos, mas com a incorporação aliados a inovação transformam-se em vantagens duradouras e ate mesmo exclusivas em alguns casos.

Levantar questões que possibilitem a discussão do assunto mais afundo pelas empresas é um propósito da mídia e de muitas organizações conhecedoras do tema, espera-se que, na medida em que o modelo apresentado seja testado e colocado na rotina da empresa que ainda não possui esse sistema, verifique a consistência e aplicabilidade na mesma podendo utilizar mais de um instrumento de avaliação da sustentabilidade e compreendendo a dinâmica da competitividade.

O cliente esta cada vez mais exigente e consciente daquilo que consome, ou seja, esta consumindo melhor e com maior preocupação com o meio ambiente, devido a esse fator, o empresário busca melhores maneiras de trazer esse cliente em potencial a sua empresa e ate mesmo fidelizá-lo a ela, os meios de comunicação explodiram artigos e matérias a respeito do assunto, diariamente somos bombardeados com tais informações que conduz ate o comportamento do cliente na hora de escolher uma marca ou empresa para realizar suas compras, exemplos como passara comprar em uma loja pelo fato da mesma utilizar de uma metodologia sustentável onde os resíduos são utilizados em prol do ambiente, ou mesmo comprar pão em uma padaria que utilizado melhor a produção não agredindo o meio ambiente a sua volta e também comprar uma vassoura feita de garrafas pet pois a empresa que as fabrica esta retirando do meio ambiente o que seria descartado agredindo o mesmo, o cliente tem a consciência de que aquela compra esta contribuindo com o ambiente ao mesmo tempo atendendo suas necessidades, que é o que o cliente deseja, atender suas necessidades sem agredir 0 meio ambiente, assim sendo as empresas buscam metodologias sustentáveis afim de satisfazer esse cliente e se tornar mais competitiva no mercado podendo oferecer algo bom pelo menor preço e com resultados positivos para ambos.

A sustentabilidade e a competitividade num primeiro momento podem parecer estarem em lados totalmente opostos, porem essas duas ferramentas estão interligadas e podem ser de grande utilidade, o que pode parecer custo, na realidade é um investimento o qual trará resultados ate maiores do que o esperado, porem é preciso um planejamento detalhado para realizar tal implementação haja vista que esse método não é um planejamento de marketing, não se pode confundir o planejamento para a colocação no cotidiano da empresa e o planejamento voltado apenas para a publicidade e promover a marca utilizando disto, deve ser algo constante e que se faça parte do cotidiano da empresa, essa conscientização se dará pelo interesse total da diretoria da empresa, sendo que a mesma deve estar atenta as atualizações do mercado para que sua equipe esteja sempre motivada a colaborar.

Como vimos o estado também tem seu papel fundamental para esse processo, já que ele institui as empresas os modelos e padrões a serem seguidos uma vez que aquela utilizara dos recursos e matérias primas disponíveis naquela região, estado este que deve fiscalizar e ao mesmo tempo apoiar as empresas com essa 
responsabilidade sustentável, incentivar as mesmas da utilização desse método ate para que possam se auto sustentarem e ate mesmo serem mais competitivas no mercado, criar políticas publicas voltadas a essa questão é somente possível se o mesmo tiver também esse compromisso. Grande parte dessas empresas - $61 \%$ espera do Governo assessoria para implementar procedimentos de gestão ambiental e identificar tecnologias limpas. Além disso, essas empresas apontaram como principal fator inibidor da prática de gestão ambiental a não-disponibilidade de informações e de recursos técnicos e financeiros. Acrescente-se que a maioria dos micro e pequenos empresários não está informada sobre os requisitos legais aplicáveis ao seu negócio nem dispõe de tecnologias limpas.

No Amapá, um dos estados mais bem preservados do país é possível observar que muitos empreendedores criam ou aprimoram ferramentas voltadas para sustentabilidade sendo estes mais competitivos em, que é 0 que o cliente busca no mercado, algo bom e de qualidade e preço justo, produtos oriundos do meio ambiente e que passam pelo processo de melhorias na produção se tornam atrativos e cada vez mais procurados no mercado, porem muitos empreendedores ainda não conseguem atender a essa demanda por falta de incentivo e deixam ate de se fazerem presentes, como ocorre com muitos empreendimentos que se vêem sem alternativas para continuar a desenvolver esse trabalho juntamente a sua empresa, pelo fato do não apoio governamental, porem ainda existem em nosso estado algumas alternativas e incentivos para essa pratica nas empresas como foi o caso de sucesso da COOPERAMARIA, incentivada por um projeto da Deputada Janete Capiberibe, onde as cooperadas fabricavam artefatos a partir de resíduos de madeira e que ganhou espaço no mercado conquistando clientes ate mesmo internacionais.

Vimos que hoje o empreendedor esta voltado a estratégias de competição sustentável, sendo que a competitividade é o foco da empresas que desejam obter uma vantagem, e hoje o mercado esta focado em produtos e processos sustentáveis, o atual empreendedor busca oportunidades de aproveitar aquilo que para muitos é descarte porem com seu poder de inovar e transformar as coisas acaba por ter resultados positivos e gerando lucro. Aproveitar melhor o que compramos, escolhendo produtos que sejam acondicionados em embalagens biodegradáveis ou redescobrir antigos costumes como, por exemplo, a volta das garrafas retornáveis de bebidas, os velhos cascos, ou das sacolas de feira para carregar compras, são atitudes que fazem uma grande diferença.

\section{Referências Bibliográficas}

BARNEY, JAY B. Resourse-based theories of competitive advantage: A ten-year retrospective on the resource based view. Journal of Management, 6, 2001, Disponivel em: $<$ http://jom.sagepub.com/cgi/content/abstract/27/6/643>

CAVALCANTE, Clóvis . Meio ambiente, desenvolvimento sustentável e politicas públicas. São Paulo: Cortes: Recife, 2002

CHAGAS, Marco Antonio. Sustentabilidade e gestão ambiental no Amapá: Saberes Tucujus:Macapá: SEMA, 2002

DORNELAS, José Carlos, Empreendedorismo: transformando idéias em negócios, Rio de Janeiro, Elsevier, 2008.

DRUCKER, Peter Ferdinand, Administrando para o futuro: os anos 90 e a virada do século, 2003.

FLEURY, A., FLEURY, M. T. Estratégias competitivas e competências essenciais: perspectivas para a internacionalização da industria no Brasil . São Carlos, Agosto de 2003.

http://www.uninove.br/PDFs/Publicacoes/revistagerenciais/rgerenciais_v5n1/rgv5n1esp.pdf\#page=37 Acessado em 02/06/2012 as 17:36.

JÚNIOR, Arlindo Philippi e PELICIONE, Maria Cecília Focesi, editores: Educação Ambiental e Sustentabilidade, Barueri, São Paulo: Manole, 2005 
Empreendedorismo como ferramenta de desenvolvimento econômico e geração de emprego e renda: elaboração de metodologia para criação de micro e pequenas empresas

KRAMES, Jeffrey A., A cabeça de Peter Drucker, Rio de Janeiro, 2010.

PORTER, Michael. Competição: Estratégias Competitivas Essenciais. Rio de Janeiro, Campos, 1999.

Revista Brasileira de Administração, Sustentabilidade, Ano XVIII, Novembro/Dezembro de 2008 № 67

SEBRAE AMAPÁ, Histórias de Sucesso: Experiências Empreendedoras, Amapá, Macapá, 2003. 